\title{
Teaching Senior High School Mathematics: Problems and Interventions
}

\author{
Aljemedin Sakilan Jaudinez ${ }^{1 *}$ \\ ${ }^{1}$ Mindanao State University Tawi-Tawi, PHILIPPINES \\ *Corresponding Author: asjaudinez@up.edu.ph \\ Citation: Jaudinez, A. S. (2019). Teaching Senior High School Mathematics: Problems and Interventions. \\ Pedagogical Research, 4(2), em0031. https://doi.org/10.29333/pr/5779
}

Published: May 14, 2019

\begin{abstract}
The 2-year Philippine Senior High School (SHS) commenced only in 2016. This phenomenographic study aimed to describe, explain and explore the teaching of SHS Mathematics to include problems encountered and interventions done by the teachers. Two schools in Quezon City were purposively chosen to be the study site with a maximal variation sampling where 8 teacher-respondents participated in the study. Classroom observation and one-on-one interview were conducted with the aid of self-designed protocols. The Teaching Guide for each subject was also analyzed. In analyzing the data, the 5 components of qualitative data analysis by O'Connor and Gibson were employed. After preparing and organizing the data, preliminary exploratory analysis and coding process were used to narrow the data into "text segments". Themes were formed through a 3-tier phase of layering to achieve saturation. Document analysis and external checking validated the findings. Results underscore that teaching SHS Mathematics is geared towards learner-centered, contextualized and relevant curriculum. Deficiencies along suggested teaching strategies, mathematical and technology tools, performance-based activities and training have prompted teachers to become flexible and resourceful in exhausting all means to effectively deliver the intended curriculum. Lessons which were inappropriate or repeated from basic education have been disregarded which decongested the contents and competencies. Low performance of students has been attributed to students' lack of mastery of basic skills, stigma, and language used which could be aggravated with books that are user-unfriendly and erroneous. Discussions, implications, and recommendations are given.
\end{abstract}

Keywords: SHS mathematics teaching, problems and interventions, phenomenographic study

\section{INTRODUCTION}

The Philippine curricular landscape has been restructured from the former 10-year basic education into a 13year mandatory education which added Kindergarten and 2 years of Senior High School by virtue of Republic Act No. 10533, known as the "Enhanced Basic Education Act of 2013" or popularly the K to 12 Curriculum. As enshrined in the law (RA 10533), the goals of High School Education are broadened for college preparation, vocational and technical career opportunities as well as creative arts, sports, and entrepreneurial employment.

The Philippine Senior High School is composed of four (4) tracks: Academic; Technical Vocational Livelihood; Arts \& Design; and Sports. Under the Academic Track, there are four (4) strands which include Accountancy \& Business Management (ABM); Science, Technology, Engineering \& Mathematics (STEM); Humanities \& Social Sciences (HUMSS); and General Academic Strand (GAS). All SHS students regardless of their chosen career track or learning strand shall take two (2) core or general education subject in Mathematics: General Mathematics and Statistics \& Probability. Further, Mathematics subjects identified as specialized are unique to the career track or learning strand that the students chose i.e. Business Mathematics for ABM, and precalculus and basic calculus for STEM. (www.course.com.ph). Often, SHS is being criticized for over-congestion i.e. there are 31 total subjects 
required (15 core subjects \& 16 track subjects where 7 contextualized and 9 specialized); each subject has 80 hours per semester or 6.5 hours daily or equivalent to 32.5 units in the collegiate level.

The $\mathrm{K}$ to 12 Mathematics Curriculum Guide underscores the need for learners to learn and explore mathematics comprehensively and with much depth due to the fact that its value goes beyond the classroom and school. Little (2009) affirmed that the ability to compute, problem solve, and apply concepts and skills in mathematics influences multiple decisions in life. Thus, it is imperative for a Mathematics teacher to engage, facilitate and encourage learners to achieve the twin goals of mathematics (critical thinking and problem-solving), especially in the Senior high School being the concluding part of basic education.

The Commission on Higher Education (CHED) in collaboration with the Philippine Normal University (PNU), the National Center for Teacher Education, has provided the Teaching Guides in support for the implementation of the SHS Curriculum with the framework SHS for SHS, which stands for "Saysay (Meaning) - Husay (Mastery) - Sarili (Ownership)" for Senior High School (CHED and PNU, 2016).

According to Acosta and Acosta (2016), Senior High School intends to provide time for students to consolidate acquired academic skills and competencies to prepare them for the future. However, certain issues in Philippine Senior High School Mathematics Curriculum have emerged. (Estonanto, 2017; Herrera and Dio, 2016) There was low acceptability of the STEM program among key educational stakeholders such as students, parents, teachers, and administrators. This certain academic strand is also perceived to be difficult in terms of its operation. Facility and instructional resources were still the major problems to carry out the mandate of the curriculum. Lack of mastery on pre-requisite competencies was also identified in preparation for students to take Senior High School Mathematics.

As the first batch of Senior High School graduates in the Philippines enter the post-secondary chapter of their life this academic year 2018-2019, this research was conducted to investigate the concrete problems encountered by teachers in Quezon City during their two (2) years or equivalently four (4) semesters of teaching core or specialized Mathematics subjects of the program, and the actions and plans they have come up with intervention.

This study aimed to describe the teaching of the core and specialized subjects in Senior High School Mathematics to include certain deviations from and innovations along the DepEd Curriculum, problems encountered and interventions done by Mathematics Teachers. Specifically, this study sought to answer the following questions:

1. How are the following core and specialized subjects of the Senior High Mathematics taught in the classroom:

a. General Mathematics;

b. Statistics \& Probability;

c. Precalculus; and

d. Basic Calculus?

2. What are the problems encountered by teachers in teaching these core and specialized subjects along:

a. Curriculum Content;

b. Teaching Strategies;

c. Instructional Resources; and

d. Assessment Strategies;

3. What are the strategies that the teachers employed to overcome these problems?

The results of the study would serve as an impetus for curriculum developers and other stakeholders to reflect and possibly make certain alterations in the Senior High School Mathematics Curriculum in terms of its curricular content, instructional resources, suggested teaching and learning activities and assessment practices. To Department of Education, its division and district offices may consider the findings of the study as a constructive means to better prepare the Senior High School students in applying the twin goals of mathematics (critical thinking and problem-solving) in their future career and post-secondary education. To public and private Teacher Education Institutions, the results of this study would serve as a reference for instructors or professors of mathematics education in planning, designing and implementing curricula that are relevant to Senior High School Mathematics. It would then keep their mathematics pre-service teachers to be abreast of the current issues in their chosen field. To mathematics educators, this study may help them apply Forlin's review, reflect and reform design on the practices in senior high school mathematics to maximize the potentials of their students in building the nation as presently envisioned by the Department of Education. To Senior High School learners, the finding of this study would hopefully make them realize that Senior High School Mathematics has been meticulously and properly prepared for their future vocation as a productive citizen of the Philippines and that they should not take this for granted. To parents, local government officials and other supportive stakeholders, this study would serve as baseline information for them to take appropriate action in giving moral and material assistance for senior high school students who are struggling to succeed in their mathematics subjects. These include home remediation, support for production of reference materials, and the like. Future researchers and academic professionals may conduct similar study focusing on specific strategies in dealing with the problems in senior high school 
mathematics. They may also confirm or refute the findings of this study by considering a wider scope, site and subject to provide a more comprehensive assertion.

This phenomenographic study focused on the teaching, problems encountered and interventions done by the eight (8) teacher-respondents in Quezon City who have been handling core and specialized subjects in Senior High School Mathematics such as General Mathematics, Statistics \& Probability, Precalculus, and Basic Calculus. The aspects predisposed include the Curriculum Content, Teaching Strategies, Assessment Strategies, and Instructional Resources. One-on-one interview with the respondents, actual classroom observation in their class, and analysis of Teacher's Guide as made available online are the primary sources of the data for interpretation and analysis. This study was undertaken during the Academic Year 2018 - 2019.

\section{METHODOLOGY}

This study made use of a Phenomenographic Inquiry Design. According to Bernard et al. (1999), as cited by Magayon and Tan (2016), this is a type of qualitative research wherein data collection focuses on a specific phenomenon experienced by a specific group of people in a specific context. This study described, explained and explored the teaching of specialized and core mathematics subjects (General Mathematics, Statistics \& Probability, Precalculus, and Basic Calculus) in 2 Senior High Schools in Quezon City, Philippines. The teaching, problems, and interventions were investigated along four (4) predisposed aspects of teaching and learning: curriculum content; teaching strategies, instructional resources and assessment strategies.

Since the study focused on the problems and interventions in teaching senior high school as the central phenomenon, the respondents of this study were teachers who have been teaching core or specialized mathematics subject(s) in Senior High School during the Academic Year 2018-2019. Purposeful sampling of mathematics teachers was done to explore the problems they encountered and the interventions used during their course of teaching Mathematics in the Senior High School. In particular, maximal variation sampling was utilized to investigate responses from multiple perspectives to include the teacher's type of school (public or private), number of years in teaching, and subject taught.

Permissions from the School Head and the teacher-respondents were sought. After the approval, the schedules were set for the researcher to visit the school or classroom and collect the necessary data. Firstly, a 30- to 45minute actual classroom observation was conducted during the class of a specific teacher-respondent. Afterwards, a one-on-one interview with the respondent was held for about 20 to 30 minutes. During the observation, the researcher spent time more as an observer than a participant and took down descriptive and reflective fieldnotes on self-designed Observation Protocol. Data collection in the study sites was concluded by an interview. Initially, this was planned to be a focus group interview but due to difficulty in gathering the teacher-respondents together plus conflict of schedules, the researcher decided to do it on a one-on-one activity. The interview was guided by a protocol containing open-ended questions which were developed by the researcher himself. The interview protocol included the following: 1.) The teaching of the core and specialized mathematics subjects in Senior High school; 2.) The problems encountered by teachers in teaching the subject along curriculum content, teaching strategies, assessment strategies and instructional resources; and 3.) The strategies that the teachers employed to overcome these problems. The interview was audio-recorded using a smartphone. As a back-up, note-taking was also done.

In analyzing the qualitative data gathered in this study, the researcher followed the 5 components of qualitative data analysis by O'Connor and Gibson which was uploaded at www.researchgate.net in January 2013. These are: 1.) organizing the data; 2.) finding and organizing ideas and concepts; 3.) building overarching theme; 4.) ensuring reliability and validity in the data analysis and in the findings; 5.) finding possible and plausible explanations to the findings . Initially, the data gathered from both observation and interview were prepared and organized. The fieldnotes and the audio-recordings were transcribed to text data and in verbatim, respectively. Since there were only a few respondents involved covering only a limited phenomenon, hand analysis of the data was employed to have a close and hands-on feel of the responses. To explore the general sense of the data, a Preliminary exploratory analysis was utilized. Coding process then followed to narrow the data into "text segments". Themes were formed through an inductive approach passing a 3-tier phase of layering to achieve saturation as similarly done in the studies of Speller (2015); and Erdogan (2011). Since Filipino, being the National Language of the Philippines, was used during the spoken discourse, the researcher had to translate the themes built into English just as what Magayon and Tan (2016) did in their research. Findings were then represented and reported through demographic table and matrix for the problems and interventions under each aspect investigated. A narrative discussion of the themes and dialogues supporting the theme were included as well. The interpretation of the findings included personal reflections and experiences of the researcher; lessons learned from the narrative of the respondents; and comparison to related literature and studies especially with other leading educational systems and top performing countries in international assessments such as Taiwan, Korea, Singapore, New Zealand, Japan, and Brunei. Assumptions and further questions were also provided. 
The findings were validated through two triangulation strategies: document analysis and external checking. Teaching Guides for Senior High School Mathematics were downloaded and scrutinized to explore and complement the findings gathered. Then, three (3) other Senior High School mathematics teachers were asked via email to answer the same interview protocol for the consistency of the results.

Prior to the classroom observation and interview, the school administrations and the teacher-respondents were assured that responses, personal information, observation, and other data would be kept anonymous and confidential as part of research ethics. Each school head was further informed through a communication that findings of the study would be stated in a broad spectrum with no reference to a specific school or teacherrespondents. Informed Consent was provided to each respondent so that he/she could affix his/her signature to manifest voluntary participation and that confidentiality is guaranteed. Informed Consent has been emphasized to be ethically sound in a qualitative research (Mason, 2002).

\section{RESULTS AND DISCUSSIONS}

\section{Teaching SHS Mathematics}

Problem No. 1: How are the following core and specialized subjects of the Senior High Mathematics taught in the classroom:

a. General Mathematics;

b. Statistics \& Probability;

c. Precalculus; and

d. Basic Calculus Business?

Teaching General Mathematics. Students are engaged with contextualized and localized teaching approach as supported by the textbook provided by CHED. A respondent even attested that,

"There are examples in Gen Math textbook that are contextualized to the Philippine Setting such as Jeepney fare in Piecewise function. It is a good progress in contextualizing Mathematics in our country".

When the lesson is introduced, the teacher relates some concepts to daily activities of the students such as jeepney fare as a "function" of distance traveled. It's also easier to introduce the first chapter which is on function because students have already met the latter since grade 8 . Board and seat works still remain as a key assessment strategy to track learning. For mastery and understanding, around 4 to 6 examples are given to students depending on the difficulty of the topic being taught. And since performance task provided in the teaching guide requires much time, an alternative way of assessing students' performance is to combine points/ratings on lecture notebook, attendance, and portfolio. This is also a technique to help those who are from HUMSS or other tracks in lifting their failing performance in Gen Math. Since teaching Math commonly entails a longer period of explaining the solution to a certain problem, there's a little to no time provided for students to clarify and ask questions as well as rationalize key properties.

Teaching Statistics and Probability. On a particular lesson, the teacher initially discusses relevant concepts where formative assessment frequently takes place in a form of oral questioning and recitations. When the discussion has been made clear already, quiz may follow or most often, students are instructed to perform group activity or performance-based task. For example, students are asked to conduct an actual survey at home, school or community then they will present their output in the classroom. Students used MS Excel for computation of descriptive statistics as well as graphical representation of data. An alternative for those who didn't have laptops is to make or draw the charts on paper. During reporting, all students are given the chance to talk about their findings under a minimal supervision of the teacher. Calculators were also an aid in computing descriptive statistics. It is observed that students can present their output very well when they use Filipino as the language rather than English. Jigsaw grouping has maximized various topics for the activity. The teaching of statistics and probability is interactive as well as experiential.

Teaching Precalculus and Basic Calculus. The lesson is first written on the board and students are asked to copy on their notebook. Then, concepts and procedures are explained by the teacher with a minimal oral inquiry for the students. A step-by-step procedure for solving problems in calculus which included limits, continuity, derivatives, and integrals is often demonstrated by the teacher where students are seated and trying to follow the teacher articulating the topic. After a lesson, a short quiz normally follows. The teacher is also encouraging the students to solve problems at home for mastery of the computational skills. Formulas were also emphasized which students should memorize. Geometric figures such as conic sections and graphs of algebraic and transcendental functions were also illustrated carefully to produce a precise visual image of the curves. Students are asked to draw these on graphing papers.

The succeeding findings on Problems 2 and 3 are intertwined in a matrix to provide for concurrency in the problems encountered by the teacher-respondents in teaching SHS Mathematics vis-à-vis the interventions made. 


\section{Problems and Interventions}

Problem No. 2: What are the problems encountered by teachers in teaching these core and specialized subjects along:

a. Curriculum Content;

b. Teaching Strategies;

c. Instructional Resources; and

d. Assessment Strategies;

Problem No. 3: What are the strategies that the teachers employed to overcome these problems?

With regards to the problems encountered by the teacher-respondents in teaching SHS Mathematics, a significant remark was made by one of them during an interview and accordingly,

"Not all topics/ competencies will be covered at the end of the semester..., as for the references, I had to browse online and download learning materials from DepEd portal since I didn't have one."

From the statement above, it could be noted that curriculum content and instructional resources were a compelling predicament faced by the teacher. Other respondents also share the same sentiment on the coverage of the content as well as the availability of textbooks for the class.

Below outlines and illustrates the problems commonly encountered by the teachers of SHS mathematics:

\section{A. On Curriculum Content}

A.1. Repetition of certain topics from Junior High School Mathematics

Problems Encountered
There are topics already taken up in the Junior High School but still
covered intensively in Statistics and Probability and General
Mathematics.
Examples:
a. For Gen Math: Functions and relations; evaluating functions;
operations on functions
b. For Stat \& Prob: Basic terms and concepts in statistics; data
collection and presentation; measures of central tendency, other
positions, and variations

A.2. Inappropriateness of certain lessons to non-STEM students

\begin{tabular}{|c|c|}
\hline Problems Encountered & Interventions Done \\
\hline $\begin{array}{l}\text { Certain topics in General Mathematics were less if not useful to } \\
\text { SHS students from other academic strand or learning track. } \\
\text { Example: } \\
\text { a. Rational Function, Logarithmic Function: Hardly applicable } \\
\quad \text { for HUMSS students, cookery students, pastry students, etc. }\end{array}$ & $\begin{array}{l}\text { Especially if a majority of the students enrolled in } \\
\text { the section are from the non-STEM strand or } \\
\text { from other tracks, these topics are given less } \\
\text { emphasis by discussing only the most important } \\
\text { concepts and applications of rational functions. } \\
\text { Topics are sometimes selected which would suit } \\
\text { students needs based on track, strand, and } \\
\text { achievement as well. }\end{array}$ \\
\hline
\end{tabular}

A.3. Too many lessons and competencies in SHS Mathematics

\begin{tabular}{|l|l|}
\hline Problems Encountered & Interventions Done \\
\hline Not all topics and competencies set by the DepEd can be covered & Teacher takes leeway in teaching the subject since \\
due to students' learning needs, class routines, holidays, suspension & quality can never be compromised just to cover \\
of classes and the like. The depth of the content, as well as the & every topic. Thus, lessons to be taught are selected \\
application sections, cannot be explored especially in pre-calculus & in order of relevance. Complexity is also \\
and basic calculus. & $\begin{array}{l}\text { considered. Extremely difficult lessons for SHS } \\
\text { students are skipped. }\end{array}$ \\
Examples: & \\
a. Final Chapter in Gen Math: Logic (Chapter 10) & \\
b. Final Chapter in Stat \& Prob: Correlation \& Regression \\
$\quad$ (Chapter 6) \\
c. Last few lessons in Pre-cal: trigonometric identities, inverses, and \\
equations, polar coordinate system \\
d. Last few lessons in Basic Cal: differential equations and definite \\
integrals
\end{tabular}




\section{B. On Teaching Strategies}

B.1. Lack of recommended teaching strategies for difficult topics in Math

\begin{tabular}{|l|l|}
\hline Problems Encountered & Interventions Done \\
\hline $\begin{array}{l}\text { Thifficult lessons are not abundantly reinforced with teaching tips. } \\
\text { and-talk where the teacher is explaining and writing everything on } \\
\text { the board while the students are listening and trying to follow the } \\
\text { instruction. }\end{array}$ & $\begin{array}{l}\text { Group work is done instead of the usual } \\
\text { individual seat work so that students could learn } \\
\text { from their peers. Differentiated instruction is used } \\
\text { to provide an appropriate learning experience for } \\
\text { ech student who has different math achievement. } \\
\text { Math deviation also helps in breaking silence in } \\
\text { the class. Realistic teaching strategy is often used } \\
\text { by giving examples which are related to everyday } \\
\text { activities. As many computational examples as } \\
\text { possible are given. There are also a lot of teaching } \\
\text { techniques available online which may be adopted } \\
\text { in the classroom. }\end{array}$ \\
\hline
\end{tabular}

B.2. Difficulty in teaching Math using English as the medium of instruction

\begin{tabular}{|l|l|}
\hline Problems Encountered & Interventions Done \\
\hline
\end{tabular}

In Mathematics subjects and textbooks, English is the medium of Students who are good at English are asked to instruction. However, despite the fact that English is the $2^{\text {nd }}$ explain the Math problems to the class. language of Filipinos, most of our SHS students could hardly Oftentimes, the Filipino language is used in comprehend especially straight conversation. It even takes time to explanation since most of them are having a hard explain word problems, definitions, theorems, etc. because the time understanding English.

teacher needs to translate and explain them in Filipino, the first language.

\section{On Instructional Resources}

C.1. SHS Math books are lacking, user-unfriendly and erroneous

\begin{tabular}{|c|c|}
\hline Problems Encountered & Interventions Done \\
\hline $\begin{array}{l}\text { Teaching SHS Mathematics has started in } 2016 \text { without any } \\
\text { references provided. CHED released the teaching guide for each } \\
\text { subject in the middle of the academic year already and mass training } \\
\text { had been conducted after. Textbooks came after a year. Textbooks, } \\
\text { particularly for Statistics \& Probability, Pre-calculus and Basic } \\
\text { Calculus, are not provided by the DepEd. Books claimed to be "K } \\
\text { to } 12 \text { compliant" are generally less appropriate for a typical SHS } \\
\text { student in terms of difficulty, complexity, and context; and are } \\
\text { observed to be erroneous. }\end{array}$ & $\begin{array}{l}\text { Teaching guides were browsed online and } \\
\text { downloaded from the DepEd portal. The internet } \\
\text { is used for advanced research especially for highly } \\
\text { complex topics for SHS students. There are video } \\
\text { tutorials in youtube which explain topics in } \\
\text { calculus and inferential statistics in detailed. }\end{array}$ \\
\hline
\end{tabular}

C.2. Lack of mathematical tools suggested for teaching

\begin{tabular}{|l|l|}
\hline Problems Encountered & Interventions Done \\
\hline In Statistics \& Probability, spreadsheet programs such as MS Excel & Instead of incorporating relevant technology \\
which are similarly important as calculators in computation and & tools, an alternative is to apply traditional ways of \\
graphical presentations as well cannot be introduced in SHS. The & manual computation with calculators as well as \\
same is true with computer algebra systems and other programs & using easily available graphing materials in \\
which could improve achievement in calculus. This is because & statistical computations, graphical presentation of \\
there's a lack of facility and computers in school. Powerful graphing & data, sketching geometric models of functions and \\
calculators and utilities are not available. Not all students can afford & curves, computations of trigonometric functions \\
to bring a scientific calculator for their trigonometry lessons. & of angles, and the like. \\
\hline
\end{tabular}

\section{On Assessment Strategies}

D.1. Poor foundation of students in computational skills

\begin{tabular}{|l|l|}
\hline Problems Encountered & Interventions Done \\
\hline $\begin{array}{l}\text { In general, students have a poor foundation in fundamental skills } \\
\text { in Mathematics especially in problem-solving. They also lack } \\
\text { mastery of the basic skills in graphing curves and functions as well } \\
\text { as in procedural manipulation of mathematical expressions. }\end{array}$ & $\begin{array}{l}\text { lutoring is given to slow learners for them to cope } \\
\text { lo with the lesson. A long test is given prior to the } \\
\text { periodical test to exercise students. }\end{array}$ \\
\hline
\end{tabular}


D.2. Lack of proposed performance-based activities

\begin{tabular}{|l|l|}
\hline Problems Encountered & Interventions Done \\
\hline $\begin{array}{l}\text { Lessons in pre-calculus and basic calculus lack enhancement } \\
\text { activities or tasks which are performance-based. Lessons normally } \\
\text { conclude with practice exercises and tests. }\end{array}$ & $\begin{array}{l}\text { To give account for the performance of the } \\
\text { students, the teacher requires students to submit } \\
\text { their lecture notebooks, portfolios and worked- } \\
\text { out activities. Attendance is also considered. }\end{array}$ \\
\hline
\end{tabular}

\section{Teaching SHS Core Mathematics}

General Mathematics and Statistics \& Probability are the two (2) core subjects intended for Grade 11 or 12 Senior High School Students (Age 16 or 17), regardless of their chosen career track or learning strand. Each subject is required to be taught for 80 hours per semester. General Mathematics covers topics on rational, exponential and logarithmic functions, business mathematics and logic. On the other hand, Statistics \& Probability includes topics on random variables, sampling techniques and distributions, population mean and proportion, hypothesis testing, and correlation \& regression analysis. (CHED and PNU, 2016).

In the current landscape of the $\mathrm{K}$ to 10 Mathematics, Mathematics is taught in a spiral progression approach from Kindergarten to Grade 10 of the Junior High School. (K to 12 Mathematics Curriculum Guide, 2012). Thus, it is inevitable that certain topics in SHS General Mathematics or Statistics and Probability were already taken up by the students in their previous years. And this could be an opportunity to link students' prior knowledge with the new lesson. Teachers may even let their students summarize or recall their previous knowledge about the topic. However, since 1 semester is insufficient to cover all competencies, it would be wiser if introductory lessons in General Mathematics or Statistics \& Probability will be discussed in a quick pacing to accommodate key topics such as logic, hypothesis testing, correlation, and regression.

In General Mathematics, there are certain contents which seem to be less if not useful for SHS students from other academic strand or learning track and yet these are still given to them as provided by the Curriculum Guideline. However in Taiwan, SHS students in their final and $3^{\text {rd }}$ year (Age 17 years old) will take a full-year mathematics course designed with a different focus and weight to fit the vocational needs and programme arrangement in Sciences, Engineering, Medicine, Social Sciences, Humanity, Law, Education, Arts, and other fields. And in Korea, Mathematics is even made optional in grades 11 and 12 (Ages 16-17) where other mathematics subjects can be chosen freely according to students' interest, aptitude and career path (Hodgen, et al., 2010). Students should learn these core subjects comprehensively and with much depth to help them in their future career or university education. After all, not all topics and competencies set in these subjects may be covered due to certain compelling factors and circumstances.

Aside from the "disconnect" between students and the subject matter previously discussed, stigma towards Mathematics along with other factors has caused students to perform poorly even in Senior High School Mathematics. This has become a lingering issue in any educational system. Consequently, students lack mastery of fundamental skills such as in procedural manipulation of mathematical expressions, graphing curves, and functions and most especially problem-solving. Teachers therefore should be more flexible and working harder on improving the performance of students. This can be done by keeping abreast of the trends and strategies in teaching mathematics effectively or perhaps applying best practices in mathematics education from Singapore and other top performing countries in international assessments such as TIMSS and PISA.

Meanwhile, the use of English as the medium of instruction in Mathematics has challenged some Filipino teachers and learners. In the K to 12 Curriculum Mathematics, communicating is considered a mathematical skill and process. However, a gap often happens in mathematical communication when students use English especially when it's not their $1^{\text {st }}$ language. In Brunei's new Mathematics curriculum, students' low performance and teaching difficulty in this subject have been attributed to the use of English as the medium of instruction in Mathematics. Khalid \& Tenga (2014) profoundly investigated the role of language and its consequences in students' mathematical communication in Brunei. From their study, it has been noted that learners are having difficulty in understanding their teacher and the textbook used given their limited English proficiency. Hence, teachers do code-switching between English and Malay in teaching Mathematics.

In the post-secondary or pre-university education in Singapore known as Upper Secondary Education, the subject Statistics and Probability is integrated in two (2) of the three (3) levels of Mathematics: Higher 1 (H1), Higher 2 (H2), Higher 3 (H3). H1 Mathematics provides a foundation in mathematics for students who intend to enroll in university courses such as business, economics, and social sciences. It covers functions and graphs, calculus and statistics. H2 Mathematics prepares students for university courses including mathematics, physics, and engineering. Topics covered include functions and graphs; sequences and series; vectors; complex numbers; calculus; permutations; combinations and probability; binomial, Poisson and normal distributions; sampling and hypothesis testing; and correlation and regression. Alongside with H2 Mathematics, students who have a strong aptitude for, and are passionate about mathematics will progress to H2 Mathematics. (Hodgen, et al., 2010). 
Current researches highlight the need to improve the pedagogical content knowledge and skills among teachers teaching of statistics and probability due to its usefulness, applicability, and importance in research. (Shuqin, 2005; Candelario-Aplaon, 2017). Lately, statistical calculation is done by the computer and the challenge is to work with various software packages in a critical way (Duller, 2008). However, not all teachers or students can have access to statistical programs and software due to cost, licensing and other factors. Thus, Giles (2002) recommended the use of Microsoft (MS) Excel as a tool in teaching statistics. Besides, it encourages a constructivist approach to learning - a salient feature of the K to 12 Curriculum (R.A. 10533, 2012; IRR, R.A. 10533, 2013).

Availability of computers has always been a subject of argument in integrating technology in Mathematics Classrooms. In New Zealand secondary schools, there is considerable inequity in the ratio of computers to students since schools rely largely on community support to purchase computers. Nevertheless, the use of MS Excel is regarded as a useful tool in exploring statistical operations. A software package known as OG Statistics was designed to interact with MS Excel which aimed to augment the teaching of Statistics in Year 13 or Grade 13. Practice problems are provided with worked solutions. Students are also encouraged to work on self-assessment modules (Giles, 2002).

\section{Teaching SHS Specialized Mathematics in STEM}

Pre-calculus and Basic Calculus are the two (2) specialized Mathematics subjects taken by Grade 11 SHS STEM Students (Age 16-18 years old) during the $1^{\text {st }}$ and $2^{\text {nd }}$ semesters, respectively. Each is required to be taught for 80 hours per semester. Pre-calculus covers topics on conic sections, nonlinear equations, series \& mathematical induction, circular \& trigonometric functions \& identities, and polar coordinate system. In basic calculus, contents would include limits, continuity, differentiation and integration of algebraic and transcendental functions, and applications on related rates, population models and areas of plane regions (CHED and PNU, 2016).

In Japan, students need to take three (3) years (grades 10, 11 \& 12) of Upper Secondary Education and is generally regarded as the most strenuous school period (Nuffic, 2015). Prospective students of science, math and medicine in higher education or university, take all the seven (7) Mathematics courses (Mathematics I, II, III, A, B $\& \mathrm{C})$ where pre-calculus or basic calculus lessons are taught along with Statistics and Probability, not as separate course of study (Hodgen, et al., 2010).

The formalism of calculus concepts generates difficulties in the teaching and learning process. Calculus is seen to be ultimately reliant on formal definitions and proofs. Thus, there's a need to contextualize and deepen the concepts in Calculus when taught (Bresoud et al., 2016; El Gaidi and Ekholm, 2015). In this manner, teaching precalculus and basic calculus lessons becomes more meaningful, realistic and profound. Further, encouraging group work and mentoring with peers among students of Calculus can harness collaboration - a key $21^{\text {st }}$-century skill where students should be equipped with. Meanwhile, Math deviation such as telling sad love story by illustrating asymptote(s) to a curve may also aid in breaking silence and in arousing the interest of students to get intrigued and thereby prepare them to learn, as what Thorndike noted in his connectionism.

Another problematic situation is on the actual gap between students' prior knowledge and the mathematical foundation of Calculus which results in poor performance. To bridge such gap, conceptual and procedural knowledge should transition along with solid computational skills being enhanced through providing solved problems and examples to students. But this should also be enhanced by performance-based assessment activities in such a way; students will realize how useful Mathematics has been in driving our civilization. And with the advancement of technology in the $21^{\text {st }}$ century, a number of online resources are available. For example, youtube provides educational videos on various problems not just in calculus but also other fields of Mathematics. The issue on lack of computers that hinders the use of Computer Algebra Systems in Mathematics Classrooms can now be provided with easily accessible alternatives. Nowadays, there are many applications such as Mathway, PhotoMath, Malmath which can be installed in smartphones where students may intelligently use as graphing utility and symbolic computation.

\section{CONCLUSIONS}

Findings and discussions of this study underscore that teaching in Senior High School Mathematics is geared towards a learner-centered approach that is contextualized and relevant to the Philippine setting. SHS Mathematics subjects specialized under STEM Academic Strand prepare students for university education particularly in medicine, science, and engineering. On the other end, SHS core Mathematics subjects provide common focus and weight for all students to apply in their chosen strand or track.

Since there's no such thing as perfect curriculum, teaching SHS Mathematics is certainly not an exception and has never been an easy task for teachers given the lack of provisions in terms of instructional resources as well as series of training during its beginning in 2016. As such, deficiencies along proposed or suggested teaching strategies for difficult topics in Math, mathematical tools for teaching, technology, performance-based activities have 
prompted teachers to become flexible, and resourceful in looking for available means which could help them effectively deliver the intended curriculum.

While it's true that there are still topics in the core subjects repeated from basic education, this became an opportunity to link students' prior knowledge in exploring a deeper and more practical mathematics. Lessons inappropriate for non-STEM students have been disregarded in teaching thereby helping decongest the contents and competencies set.

The low performance of students in content \& procedural knowledge, computational skills, visualization, problem-solving and other skills and processes in mathematics, has been attributed to students' lack of mastery of the fundamental skills, lingering stigma, and language used. This could even be aggravated when teachers continue using books and other resources that are user-unfriendly and erroneous.

\section{RECOMMENDATIONS}

Recommendations of this study are outlined as follows:

1. Teaching SHS Mathematics should center on the depth of the contents that provide relevant and different focus and weight of competencies to fit students' vocational needs. One way is by teaching the core subjects exclusively for a specific group of students under the same academic strand or learning track. For an instance, when General Mathematics is taught exclusively to students under the ABM academic strand only, lessons on business mathematics may be maximized, enhanced and deepened. Thus, other topics/ competencies which are less relevant, as well as those which have been previously taken already in the Junior High School, shall be taught in a quicker pacing if cannot be disregarded.

2. Teaching Guides in SHS Mathematics developed by CHED and PNU, as well as Learning Materials for students shall be reproduced and completely distributed to all public and private schools across the country given the diversity of schools and teachers. This will provide teachers with readily available and credible instructional resources on hand. School administrators shall ensure a one-on-one ratio of student and textbook in SHS Mathematics. This might also help promote the "Saysay (Meaning) - Husay (Mastery) - Sarili (Ownership) for SHS" Framework among students regardless of whichever school they come from.

3. The DepEd computerization program (DCP) shall be strengthened by investing on provisions of licensed software packages such as SPSS and computer algebra systems (CAS) as well as training along with the hardware which could be useful for SHS Mathematics. In this way, mathematical tools will be upgraded and modernized to transform the SHS Mathematics into a better avenue in meeting the challenges of the $21^{\text {st }}$ century.

4. Since performance tasks account for the largest percentage in the grading system, $50 \%$ for the core subject and $45 \%$ for the specialized subject, appropriate performance-based activities in SHS Mathematics along with the corresponding rubrics or scoring guide shall be provided and suggested by the DepEd and/or other authority.

5. Teachers should exhaust all efforts in employing effective teaching and assessment strategies, and appropriate instructional resources in SHS Mathematics to fit lessons in the functional skills and college readiness standards foundational skills articulated by DepEd and CHED, respectively.

6. Schools are encouraged to adopt Placement Test as part of admission for incoming Senior High School Students. The purpose is to determine which academic strand or vocational skill level a prospective SHS student can enroll to. With this, students taking up STEM strand are expected to be ready in taking Mathematics specialized subjects (pre-calculus and basic calculus).

7. DepEd should adopt its own Curriculum Framework for Senior High School Mathematics which shall undergo regular evaluation where teachers teaching SHS Mathematics shall be part of. Constructive feedback from other stakeholders shall also be considered to be a basis for a revision of or an amendment to the existing curriculum. The curriculum evaluation shall include aspects on but not limited to curriculum content, teaching strategies, instructional resources, and assessment strategies. National Trainings for teachers shall then follow at least 2 months before the new features of the curriculum will be implemented.

8. Similar studies on the teaching of SHS Mathematics may be conducted by other researchers to either support or refute the findings of this paper.

\section{REFERENCES}

Acosta, I. C. and Acosta, A. S. (2016). Teachers' Perceptions on Senior High School Readiness of Higher Education Institutions in the Philippines. Universal Journal of Educational Research, 4(10), 2435-2450. https://doi.org/10.13189/ujer.2016.041024

Braza, M. T. and Supapo, S. S. (2014). Effective Solutions in the Implementation of the K to 12 Mathematics Curriculum. SAINSAB, 17, 12-23. Available from https://www.researchgate.net/profile/Miranda_Yeoh 
Bressoud, D., et al. (2016). Teaching and Learning of Calculus. ICME-13 Topical Surveys. https://doi.org/10.1007/978-3-319-32975-8_1

Candelario-Aplaon, Z. (2017). Needs Assessment of Senior High School Mathematics Teachers in Teaching Statistics and Probability. International Forum, 20(2), 143-159. Available from http://journals.aiias.edu/iforum/article (Accessed 28 November 2018).

Chua, V. G. (2015). Assessment of the Mathematics Curriculum in the SHS Modelling Program. https://doi.org/10.13140/RG.2.1.2340.7849

Courses.com.ph (n.d.a). Senior high school core subject: statistics and probability. Available from https://www.courses.com.ph/senior-high-school-core-subject-statistics-and-probability/ (Accessed 28 November 2018).

Courses.com.ph (n.d.b). Senior high school in the Philippines: Curriculum breakdown. Available from https://www.courses.com.ph/senior-high-school-in-the-philippines-curriculum-breakdown/ (Accessed 28 November 2018).

Duller, C. (2008). Teaching Statistics with Excel: A Big Challenge for Students and Lecturer. Austrian Journal of Statistics. 37(2), 195-206. https:// doi.org/10.17713/ajs.v37i2.300

El Gaidi, K. and Ekholm, T. (2015). Contextualizing Calculus with Everyday Examples to enhance Conceptual Learning. American Society for Engineering Education, 22 ${ }^{\text {nd }}$ Conference, ID \# 12007. Available from http://www.asee.org

Erdogan, A. (2011). Preservice Mathematics Teachers' Conceptions of and Approaches to Learning: A Phenomenographic Study. Energy Education Science \& Technology Part B: Social and Educational studies, 4(1), 21-30. Available from https://www.researchgate.net

Estonanto, A. J. (2017). Acceptability and Difficulty of STEM Track Implementation in Senior High School. Asia Pacific Journal of Multidisciplinary Research, 5(2), 43-50. Available from https://www.apjimr.com

Giles, O. (2002). Using Excel to Teach Statistics in New Zealand Secondary Schools. ICOTS6. Available from https://iase-web.org/documents/papers/icots6 (Accessed 28 November 2018).

Herrera, C. D. and Dio, R. V. (2016). Extent of Readiness of Grade 10 students for General Mathematics of Senior High School in Sorsogon City, Philippines. Asia Pacific Journal of Education, Arts and Sciences, 3(4), 1-8. Available from https://www.apjeas.apjmr.com

Hodgen, J., Pepper, D., Sturmam, L. and Ruddock, G. (2010). An International Comparison of Upper Secondary Mathematics Education. Nuffield Foundation. Available from https://www.nuffieldfoundation.org/sites/default/ files (Accessed 2 December 2018).

Khalid, M. and Tengah, M. (2014). Communication in Mathematics: The Role of Language and its Consequences for English as Second Language Students. Revised Edition. Available from https://www.researchgate.net/publication/255570949 (Accessed 2 December 2018).

Little, M. E. (2009). Teaching Mathematics: Issues and Solutions. Teaching Exceptional Children Plus, 6(1). Available from https://www.scholarship.bc.edu

Lomibao, L. S. (2016). Enhancing Mathematics Teachers' Quality through Lesson Study. SpringerPlus Open Access. 5, 1590. https://doi.org/10.1186/s40064-016-3215-0

Magayon, V. C. and Tan, E. B. (2016). Learning Mathematics and Differentiated Instruction in the Philippines: A Phenomenographical Study on Struggles and Successes of Grade 7 Students. International Journal of Educational Studies in Mathematics, 3(3), 1-14. Available from https://www.ijesim.com

Mason, J. (2002). Qualitative Researching. SAGE Publication. 2nd Edition. Pp. 80-82. Available from https://www.sxf.uevora.pt

Nuffic. (January 2015). Education System Japan. $1^{\text {st }}$ Edition, Version 4. Available from https://www.nuffic.nl/documents/367/education (Accessed 2 December 2018).

O'Connor H. and Gibson N. (n.d.) A step-by-step guide to Qualitative Data Analysis. Pimatizinin: A Journal of Aboriginal and Indigenous Community Health, (1). Available from https://www.researchgate.net

Official Gazette of the Philippines (2013). IRR Republic Act No. 10533. Available from http:/ /www.officialgazette.gov.ph (Accessed 25 November 2018).

Orale R. and Sarmiento D. (2016). Senior High School Curriculum in the Philippines, USA, and Japan. Journal of Academic Research, 1(3), 12-23. Available from https://www.researchgate.net

Philippines. Commission on Higher Education and Philippine Normal University (2016). Teaching Guide for Senior High School Basic Calculus. Available from https://www.course.com.ph (Accessed 25 November 2018).

Philippines. Commission on Higher Education and Philippine Normal University (2016). Teaching Guide for General Mathematics. Available from https://www.course.com.ph (Accessed 25 November 2018).

Philippines. Commission on Higher Education and Philippine Normal University (2016). Teaching Guide for Senior High School Pre-calculus. Available from https://www.course.com.ph (Accessed 25 November 2018). 
Philippines. Commission on Higher Education and Philippine Normal University (2016). Teaching Guide for Senior High School Statistics and Probability. Available from https://www.course.com.ph (Accessed 25 November 2018).

Philippines. Department of Education (2012). K to 12 Mathematics Curriculum Guide. Available from http://www.deped.gov.ph

Reston, E. D. and Loquias, C. M. (2018). Improving Statistical Pedagogy among K to 12 Mathematics Teachers in the Philippines. ICOTS. Available from https://iase-web.org/icots/10/proceedings/pdfs/ICOTS10

Senate of the Philippines (2012). R.A. 10533: "Enhanced Basic Education Act of 2013". Available from http://www.senate.gov.ph

Shuqin, Y. (2005). Applications of Excel in Teaching Statistics. CAL-laborate, (5). Available from https://openjounals.library.edu.au/index.php/CAL/article (Accessed 28 November 2018).

Speller, S. (2015). Mathematics Teacher's Experience with Flipped Learning: A Phenomenographic Approach. Dissertation. University of Toledo. Available from https://etd.ohiolink.edu 